\title{
Modelling the effects of land-cover changes on surface climate in the Mediterranean region
}

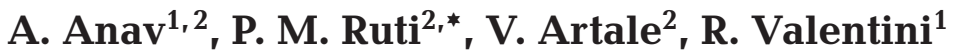 \\ ${ }^{1}$ Department of Forest Resources and Environment (DISAFRI), University of Tuscia, Viterbo, Italy \\ ${ }^{2}$ Italian National Agency for New Technologies, Energy and Sustainable Economic Development (ENEA), Rome, Italy
}

\begin{abstract}
We investigated the impact of land-cover changes on regional climate over the EuroMediterranean area. For this purpose, we compared a control simulation, which employs the presentday vegetation cover, with 2 different potential vegetation distributions performed with the regional climate model RegCM3 for the time period 1981-2000. The simulation results show how land-cover changes are able to modify both the thermodynamics and dynamics of the lower troposphere in central Europe, particularly during summer. Within some of the regions where land-cover change occurred, we found significant changes in heat fluxes, while weak changes were found in surface temperature and precipitation fields. Changes in vegetation composition modify the probability density function of the $2 \mathrm{~m}$ temperature, and hence land-cover changes may have a strong impact on extreme events.
\end{abstract}

KEY WORDS: Land-cover changes $\cdot$ Land-atmosphere interactions $\cdot$ Climate $\cdot$ Extreme events Resale or republication not permitted without written consent of the publisher

\section{INTRODUCTION}

Land-use and land-cover changes (LCCs) affect the local, regional and global climate system through biogeophysical and biogeochemical processes (Pielke et al. 2007) that modify surface-atmosphere exchanges of momentum, energy and greenhouse gases as well as surface roughness (Xue \& Shukla 1993, Xue \& Shukla 1996, Fahey \& Jackson 1997, Betts 2001, Pitman 2003, Nosetto et al. 2005, Findell et al. 2007, Pielke et al. 2007).

The feedback mechanisms between the land surface and the atmosphere have been increasingly investigated during last decade due to increasing computational power. Therefore, in order to study the potential impacts of LCCs on local climate, the simulations performed by general circulation models (GCMs) can be complemented by the use of regional climate models (RCMs); in fact, the coarse resolution of the GCMs limits their capability to capture mesoscale features that play a pivotal role in regional dynamics (Giorgi \& Mearns 1991, Christensen et al. 1997, Gaertner et al. 2001, Seneviratne et al. 2006).

Recent studies suggest that in continental midlatitudes, soil plays a similar role to that of the ocean, but instead of storing heat, it stores water during the wet season and moistens the atmosphere by evapotranspiration during the dry season (Heck et al. 2001, Koster et al. 2004). Some GCM studies suggest that in Europe the summer (dry season) soil moisture anomalies do not have a substantial impact on precipitation (Koster et al. 2004, Seneviratne et al. 2006). Nevertheless, regional climate simulations emphasize the importance of soil moisture-temperature and soil moisture-precipitation feedbacks in influencing summer climate variability in Europe (Christensen et al. 1997, Ruti et al. 1998, Seneviratne et al. 2006). These differences between GCM and RCM results might come from the different parameterizations of individual processes and the amplification of the differences by the nonlinearity of the models. However, it is important to note that RCMs provide an increase in resolution and can capture physical processes and feedbacks occurring at regional or local scales that GCMs are not able to describe due to the coarse resolution. As such, RCMs are highly suited for regional studies.

Vegetation cover, particularly over Europe, has changed markedly over the last few centuries due to human activities converting forests into arable land or 
pasture. This has, in turn, had a considerable influence on regional climate (Reale \& Shukla 2000). Potential resulting impacts from vegetation changes include changes in the radiation budget via the surface albedo and changes in the hydrological cycle mainly in terms of evapotranspiration, precipitation and runoff (Findell et al. 2007).

Several attempts to study and quantify the effect of LCCs on climate exist for Europe. Dumenil-Gates \& Ließ (2001) found a slight cooling at the surface (1 K) related to the increased surface albedo that, in turn, reduced the input from net solar radiation at the surface, and reduced precipitation during the summer as a result of less evapotranspiration of plants in a deforestation experiment. The opposite was found for an afforestation experiment. For winter, no significant signals have been found due to the strong influence of the mid-latitude baroclinic disturbances (Dumenil-Gates \& Ließ 2001). Sanchez et al. (2007) performed a simulation where they substituted trees with grass, and found a significant decrease in summer precipitation of up to $3 \mathrm{~mm} \mathrm{~d}^{-1}$ due to lower evapotranspiration and an increased surface temperature of up to $3 \mathrm{~K}$. In Heck et al. (2001), afforestation caused a maximum cooling of $2 \mathrm{~K}$ during May, while during August a warming of $1 \mathrm{~K}$ was observed. This sign reversal is a direct consequence of the faster springtime drying out of the soil moisture in the afforestation simulation. Owing to deeper roots and larger leaf area, transpiration in the afforestation simulation is increased during spring, leading to a moister and cooler spring. Higher evapotranspiration rates lead to a faster springtime drying out of the soil than in the control run. Consequently, by the middle of July, soil moisture has reached a critical low value in the afforestation simulation and evaporation is inhibited, while exchanges of sensible heat are enhanced. From this moment onward, evapotranspiration and soil moisture loss are larger in the control run and the sensitivity of latent heat and soil moisture loss to vegetation changes sign, leading to a drier and warmer summer. For precipitation, however, no significant differences were found. In general, these examples reveal that the magnitude, location and direction of changes vary among studies and appear to be dependent on the specifics of the land model parameterization (Findell et al. 2007).

The aim of the present study was to corroborate previous results while exploring new LCC patterns. For this purpose we examined the changes in regional climate as a consequence of both anthropogenic deforestation, occurring mainly in eastern Europe where there is a progressive substitution of natural forests with crops (Middleton \& Thomas 1997), and a potential natural vegetated state. The potential natural landcover distribution approximates the land-cover condi- tions that would exist in the absence of human disturbances (Reale \& Shukla 2000). To achieve this objective we imposed different land covers as boundary conditions to the hydrostatic regional climate model RegCM3.

A further objective of the present study was to analyze the impact of LCCs on weather extremes. The European heat wave of summer 2003 has received considerable attention both because of its potential link to larger-scale warming patterns (e.g. global warming) and because of the extensive loss of life (Fouillet et al. 2006, Zaitchik et al. 2006). Several studies found that this regional heat wave was quite unique in comparison to the instrumental climate record (Schär et al. 2004). It is also been shown that the amplitude of the heat wave could be amplified by land surface preconditioning (Ferranti \& Viterbo 2006, Vautard et al. 2007). Here we assessed the influence of LCCs on surface temperature extremes.

\section{METHODS}

\subsection{Model description}

In order to assess the impacts of LCCs on regional climate, we performed 3 different simulations conducted with a regional climate model. The experiments differ solely in the definition of land-use category in terms of type of vegetation cover. We used the regional climate model RegCM3, a primitive equation, hydrostatic, compressible, $\sigma$-vertical coordinate model initially developed by Giorgi (1990) and Giorgi et al. (1993a,b) and then modified by Giorgi \& Mearns (1999) and Pal et al. (2000). RegCM3 is widely used for regional climate simulations both in the standalone version and coupled to the ocean (Artale et al. 2009). A detailed description of key model features can be found in Pal et al. (2007). We ran the model from 1981 to 2000 using the first year as spin up. A $20 \mathrm{yr}$ simulation ensured that we would see how surface climate changes with respect to land cover changes, while we found that a 1 yr spin up was enough to initialize the soil moisture.

The model domain was centered around Italy at $41^{\circ} \mathrm{N}$ and $15^{\circ} \mathrm{E}$ and was projected on a Lambert conformal grid covering almost all of Europe (except northern Scandinavia and Iceland) and North Africa; the domain covers $160 \times 150$ grid points in the longitudinal and latitudinal directions, respectively, with a horizontal resolution of about $30 \mathrm{~km}$. At this fine resolution, the main topographic features of the domain are captured; the model domain and topography are shown in Fig. 1. We set vertical coordinates to $18 \sigma$ levels with the top at $50 \mathrm{hPa}$. 


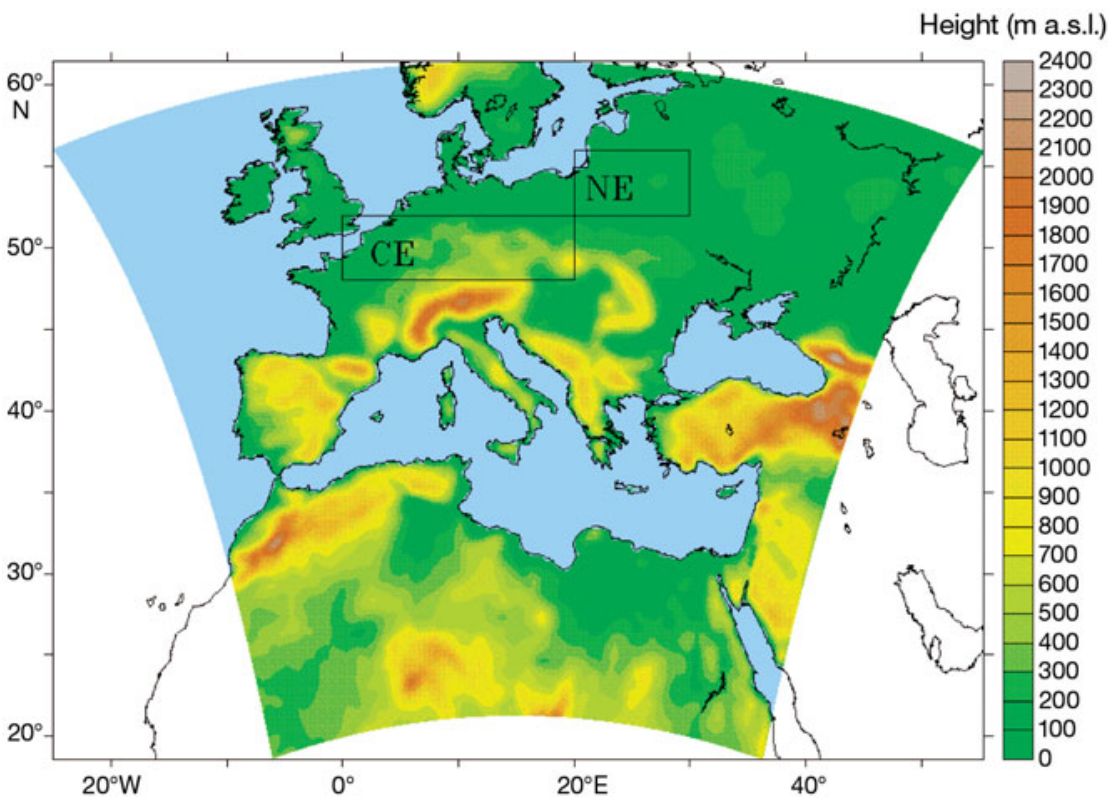

Fig. 1. Domain and topography of the regional climate model RegCM for the land-cover change simulation. CE: central Europe; NE: northeast Europe

porosity, minimal soil suction and moisture content relative to saturation (Dickinson et al. 1993).

The surface vegetation and land-use types were obtained from a global data set derived by the US Geological Survey from satellite information (Loveland et al. 1991); each grid element is assigned a dominant type of land cover (Dickinson et al. 1993).

We performed 3 simulations to assess the impacts of LCC on regional climate. In the first experiment (Fig. 2a), the Global Land Cover Characterization (GLCC; Loveland et al. 2000) data set was used, which represents the presentday vegetation cover (i.e. control, CTL) over Europe. The second simulation (Fig. 2b) consisted of a deforestation scenario (DEF): starting from the GLCC data set, we substituted all the forests and trees below $800 \mathrm{~m}$ with crops and/or mixed farming. This simulation

Lateral boundary conditions, required to run the model, were provided by the European Centre for Medium-Range Weather Forecasts (ECMWF) reanalysis data (ERA40, Uppala et al. 2005) with a resolution of $2.5 \times 2.5^{\circ}$; these were interpolated via the relaxation method described by Giorgi et al. (1993b) into the model lateral buffer zone. RegCM3 also requires sea surface temperature (SST) as a boundary condition, which is interpolated into the model grid from the corresponding $1^{\circ}$ NOAA fields (Reynolds et al. 2002).

Several simulations have been performed in the Euro-Mediterranean area using RegCM3; a detailed description of the model performances for the present climate can be found in Giorgi et al. (2004), Jacob et al. (2007) and Artale et al. (2009).

\subsection{Potential vegetation}

The exchange of heat, water and momentum between soil, vegetation and atmosphere is simulated in RegCM3 by the hydrological process model Biosphere-Atmosphere Transfer Scheme (BATS; Dickinson et al. 1993). BATS divides the land surface into 18 types (Fig. 2) and the soil into 12 types (Dickinson et al. 1993). These 18 classes of land cover are used to define a wide variety of land surface, hydrological and vegetation properties; each vegetation class, in fact, has associated values of roughness length, albedo, leaf area index, rooting depth and the fraction of water extracted by the roots (Dickinson et al. 1993). As for the 12 soil types, each of these has associated values of may be representative of the LCC occurring mainly over eastern Europe (Fig. 2b), where there is a progressive deforestation leading to a substitution of forests with crops (Middleton \& Thomas 1997). The third simulation (Fig. 2c) was an afforestation scenario (AFF) which considered a potential natural land-cover distribution that approximates the land-cover conditions that would exist in the absence of human disturbance (Reale \& Shukla 2000).

\section{RESULTS}

\subsection{Comparison of domain-averaged climate}

At the soil level, the faster and significant response to LCCs occurred in the surface energy budget, mainly in summer. The European winter climate, on the other hand, was influenced by synoptic-scale disturbances which were advected into the model domain through its lateral boundaries. Most plant activity is expected to take place in summer, as are the interaction mechanisms that take place between vegetation and climate. As a consequence, vegetation-induced effects cannot locally accumulate to substantial amplitudes in winter, and only weak changes were found. In light of this, we decided to consider the summer only in further analysis.

The differences (and relative changes) in domainaveraged latent heat and sensible heat fluxes between the different experiments and the CTL run are presented in Table 1. It is noteworthy that these differences (and relative changes) are weak, and significant 

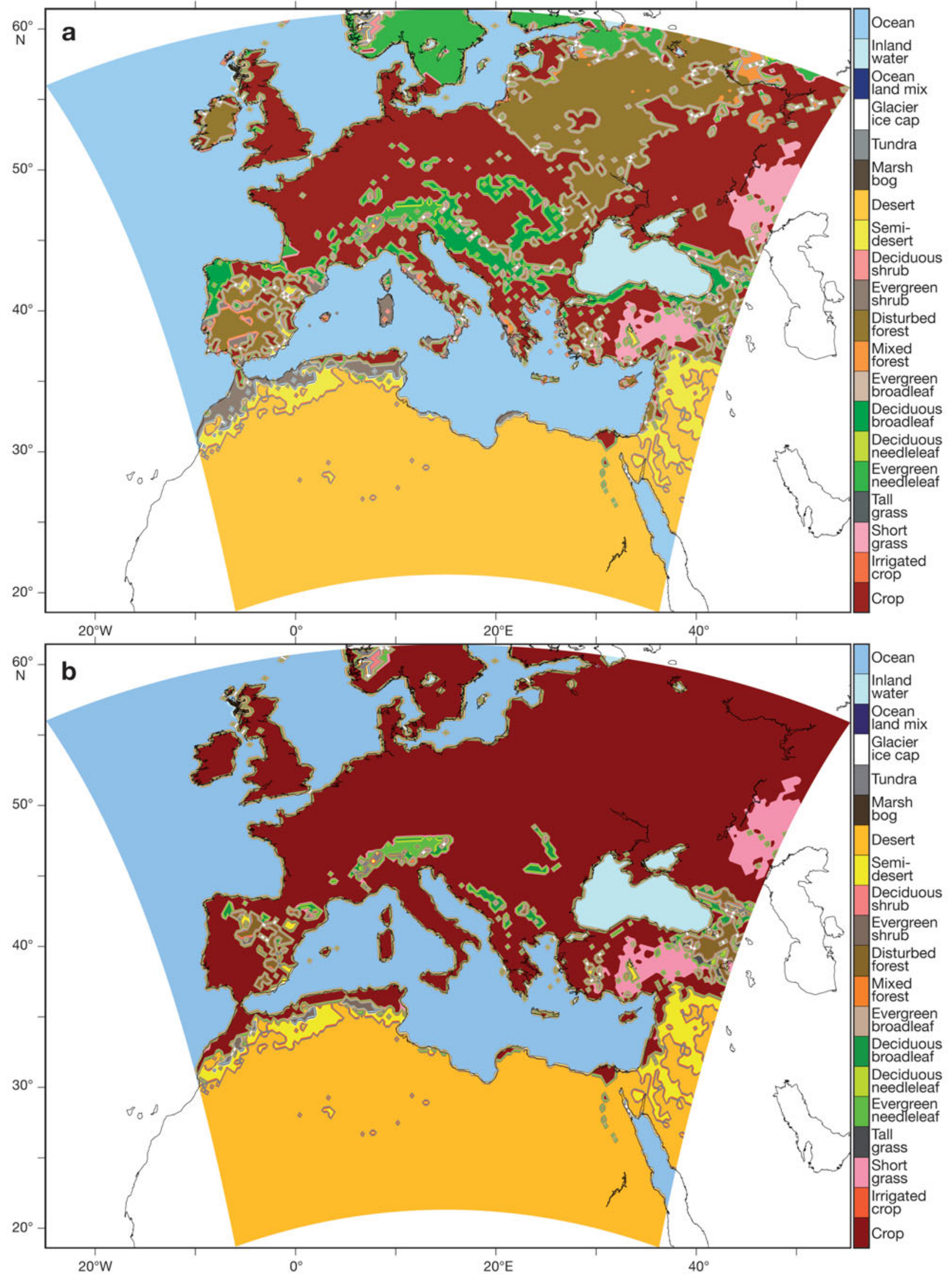

Fig. 2. Geographical distribution of vegetation types and land use types in Europe for (a) control, (b) deforestation and (c) afforestation simulations 


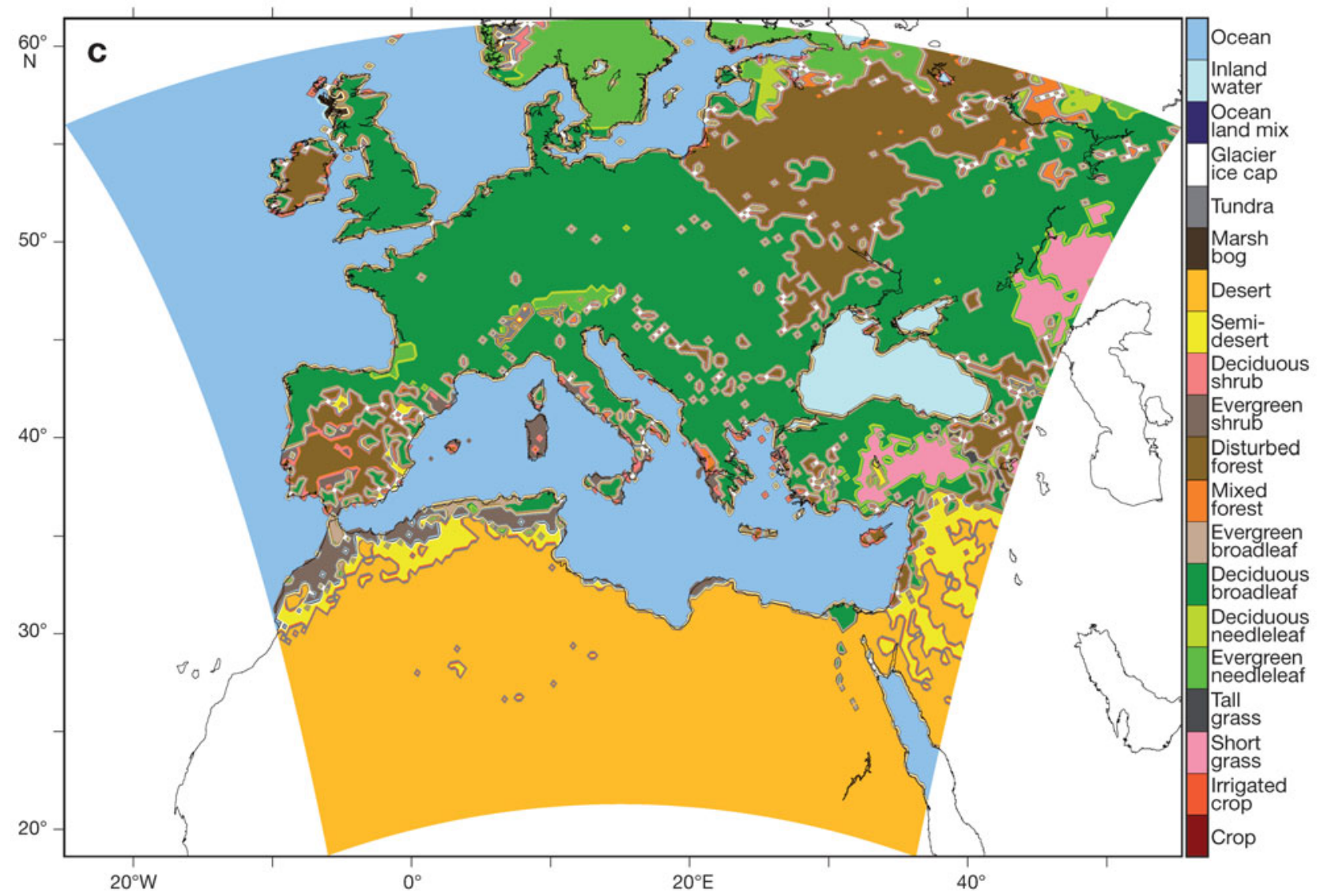

Fig. 2 (continued)

Table 1. Differences (and relative changes, \%) in domainaveraged heat fluxes $\left(\mathrm{W} \mathrm{m}^{-2}\right)$ between the land-cover change simulations (DEF: deforestation; AFF: afforestation) and the control (CTL) run. The time averages have only been computed for the land points in the period 1982-2000 and only for the summer season. Bold: changes that are statistically significant $(t$-test, $\mathrm{p}<0.05)$

\begin{tabular}{|lcc|}
\hline Variable & DEF-CTL & AFF-CTL \\
\hline Latent heat & $0.15(0.3)$ & $-0.92(-1.87)$ \\
Sensible heat & $\mathbf{- 2 . 4 2 ( - 3 )}$ & $\mathbf{2 . 0 1 ( 2 . 5 )}$ \\
\hline
\end{tabular}

only in the case of sensible flux. This result was partially expected because the mean over all the land points of the domain and the entire period of simulation produce a smoothing for these variables and only a small difference from the CTL run.

The interannual variability in domain-averaged latent and sensible heat fluxes for the 3 different experiments are shown in Fig. 3. The time series show a similar behavior between CTL, DEF and AFF simulations, with marked interannual variability. The LCCs modulate the amplitude of the sensible and latent heat fluxes, leaving unchanged the interannual variability, which is mainly driven by the general circulation (i.e. lateral boundary conditions). Furthermore, an increase in latent heat flux corresponds to a decrease in sensible heat flux, according to the Bowen ratio conservation.

However, the overall averaging shown in Fig. 3 and Table 1 could hide local significant changes of the surface fluxes induced by LCCs. Since the main significant changes between the control run and the DEF and AFF simulations are expected where the LCC occurs, we selected 2 different continental regions (northeast Europe [NE] and central Europe [CE]) that fall where deforestation and afforestation are taking place (NE: $20^{\circ}$ to $30^{\circ} \mathrm{E}, 52^{\circ}$ to $56^{\circ} \mathrm{N}$; $\mathrm{CE}$ : $0^{\circ}$ to $20^{\circ} \mathrm{E}, 48^{\circ}$ to $52^{\circ} \mathrm{N}$ ). Over these small domains, we averaged the latent heat and sensible heat fluxes as well as net radiations, and computed a probability density function (PDF) for these variables.

In the following analysis, the summer PDFs of the 2 experiments (except NE-DEF latent heat, see also Table 2) significantly differed from the control run PDFs (Kolmogorov-Smirnov test: $\mathrm{p}<0.05$ ).

For the NE area, the latent heat flux of the CTL run (Fig. 4a) shows a slight bimodality with a main peak at around $100 \mathrm{~W} \mathrm{~m}^{-2}$ and a secondary peak at $80 \mathrm{~W} \mathrm{~m}^{-2}$. This bimodality is mainly due to the soil moisture con- 

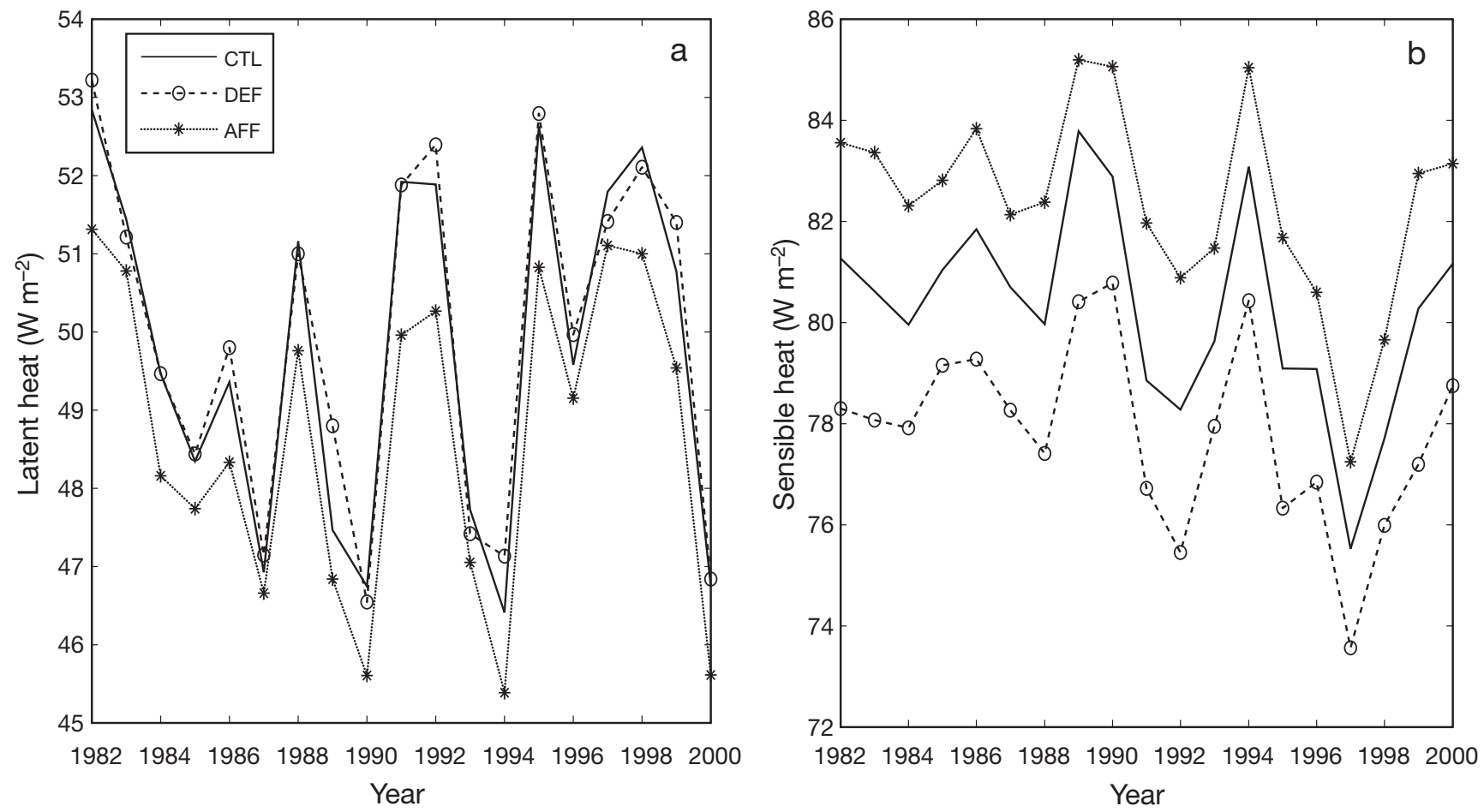

Fig. 3. Evolution of summer (June-August) (a) latent heat and (b) sensible heat fluxes for the control (CTL), deforestation (DEF) and afforestation (AFF) simulations. The time series have been computed averaging only the land points of the domain

ditions: the soil moisture is in a wet state at the beginning of the summer season (June, July), while it switches to a dry state in August, and the soil moisture depletion strongly limits the evaporation. The soil moisture PDF (data not shown) does not feature a strong bimodality, but a unimodal behavior character-

Table 2. Differences (and relative changes, \%) between the land-cover change experiments and the control run. The averages have been computed for the only land points falling in the northeast Europe (NE) and central Europe (CE) subregions, in the period 1982-2000. DEF: deforestation experiment; AFF: afforestation experiment; LAI: leaf area index; T2M: 2 m temperature; PBL: planetary boundary layer. Bold: changes that are statistically significant $(\mathrm{p}<0.05)$

\begin{tabular}{|c|c|c|}
\hline Variable & NE, DEF & $\mathrm{CE}, \mathrm{AFF}$ \\
\hline Roughness length (m) & $-0.18(-69.4)$ & $0.66(493)$ \\
\hline Albedo (fraction) & $0.005(3.1)$ & $-0.09(-44.4)$ \\
\hline LAI (unitless) & $-0.0083(-1.6)$ & $0.46(84)$ \\
\hline Stomatal resistance $\left(\mathrm{s} \mathrm{m}^{-1}\right)$ & $-61.2(-57.6)$ & $68.9(135)$ \\
\hline Root depth (mm) & $-817(-45)$ & $918(85)$ \\
\hline Latent heat $\left(\mathrm{W} \mathrm{m}^{-2}\right)$ & $3.3(3.4)$ & $-4(-3.7)$ \\
\hline Sensible heat $\left(\mathrm{W} \mathrm{m}^{-2}\right)$ & $-15.6(-43.3)$ & $9.6(36.7)$ \\
\hline T2M (K) & $0.09(0.03)$ & $-0.12(-0.045)$ \\
\hline Precipitation $\left(\mathrm{mm} \mathrm{d}^{-1}\right)$ & $0.09(3.1)$ & $-0.18(-5.7)$ \\
\hline Drag stress $\left(\mathrm{kg} \mathrm{m}^{-2} \mathrm{~s}^{-1}\right)$ & $-0.003(-16.9)$ & $0.008(51.6)$ \\
\hline PBL height (m) & $30.5(10.5)$ & $-31.4(-9.4)$ \\
\hline
\end{tabular}

ized by a peak at $25 \mathrm{~mm}$ (uppermost layer) and a heavy lower tail. Computing the same moisture PDF excluding August, the heavy lower tail disappears, highlighting the impact of the August dryness. The same behavior occurs for the latent heat flux: June-July values peak at $100 \mathrm{~W} \mathrm{~m}^{-2}$, while the August value peaks at $80 \mathrm{~W} \mathrm{~m}^{-2}$. It is also noteworthy that the total PDF of the latent heat flux shows a bimodal behavior (Fig. 4a), while the total PDF of the soil moisture is essentially unimodal. The non-linearity in the parameterization used in BATS to compute the evaporation enhances the soil moisture difference between June-July and August, producing the bimodal distribution.

The PDF of the NE-DEF latent heat flux (Fig. 4a) shows a similar shape as the NE-CTL, but with a slight shift toward higher values and a reduced frequency in comparison to the NE-CTL mean peak and an increased upper tail. Taking into consideration the relation between wind speed and heat fluxes, the increase in wind speed related to the decrease of roughness length provides a favourable condition for the exchange of latent heat flux between land and atmosphere (Suh \& Lee 2004). Also, the different winter soil moisture conditions related to the substitution of mixed forests with crops can explain the shift toward higher values in the latent heat PDF. Since deforestation reduces stomatal resistance, roughness length and root depth (Table 2), the winter evapotranspiration is de- 

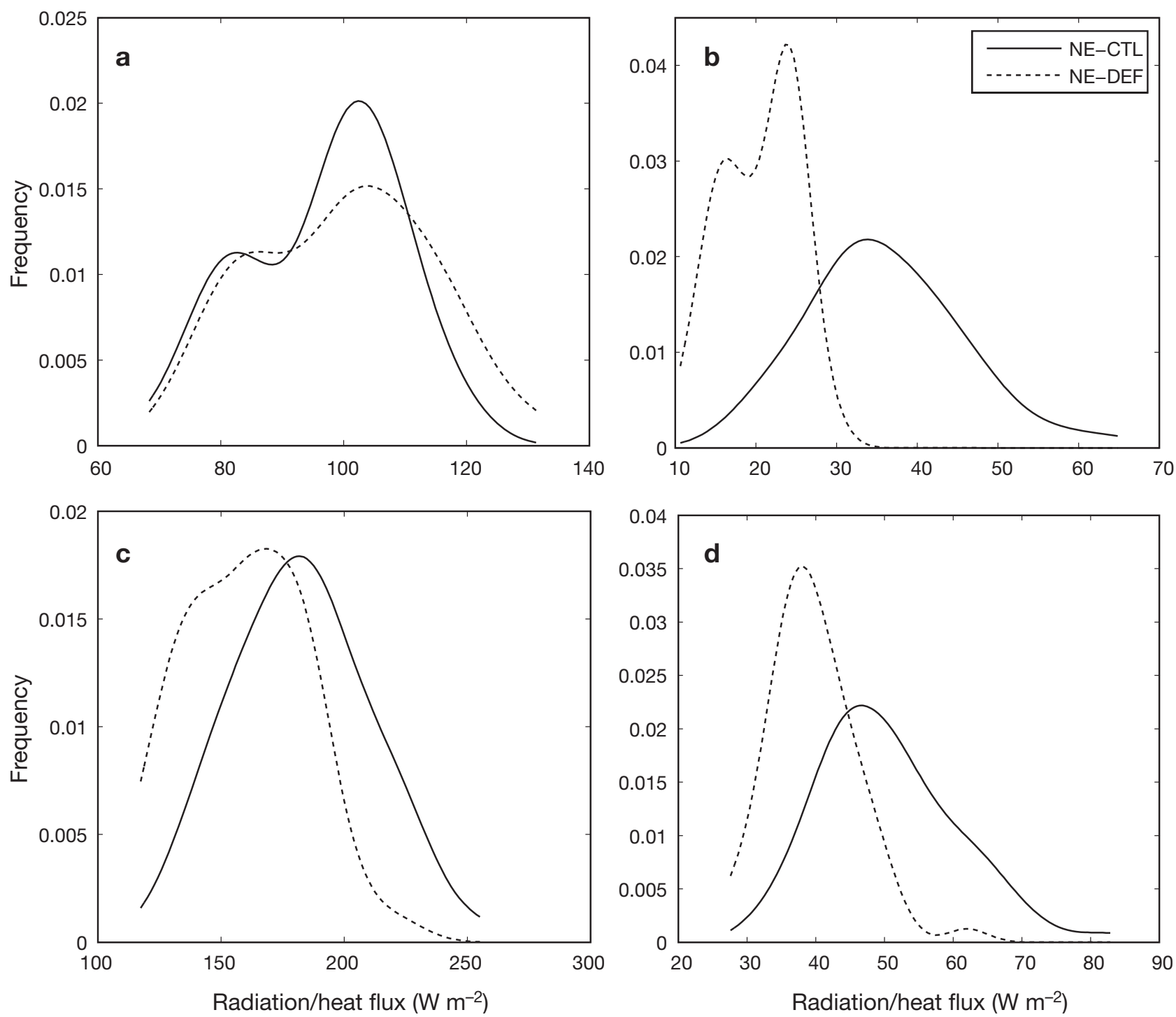

Fig. 4. Probability distribution of summer (June-August) (a) latent heat, (b) sensible heat, (c) net shortwave radiation and (d) net longwave radiation computed over a small domain falling in the deforested area $\left(20^{\circ}\right.$ to $30^{\circ} \mathrm{E}, 52^{\circ}$ to $\left.56^{\circ} \mathrm{N}\right)$. NE: northeast Europe; CTL: control run; DEF: deforestation simulation

creased (data not shown). Furthermore, in spring the soil is nearly saturated owing to snow melt in the area where deforestation occurs. Consequently, the winter evaporation reduction leads to a greater amount of water in the soil during the summer season in NE-DEF, and hence the latent heat PDF shows a slight shift toward higher values.

As for the sensible heat flux, the PDF of the NE-CTL is unimodal with a mean of about $35 \mathrm{~W} \mathrm{~m}^{-2}$, while deforestation reduces both the mean value and the standard deviation (Fig. 4b). The sensible heat flux reduction could compensate for the latent heat flux increase, i.e. the Bowen ratio is changed while the energy input is kept constant. Concerning the sensible heat flux reduction, the surface drag coefficient, which was reduced in the DEF simulation (Table 2), limits the turbulence production, and consequently the mean sensible heat flux. Moreover, within a first order approximation, the process variance is proportional to the drag coefficient and the variance of the product of wind velocity by temperature gradient. The decrease in these 2 variables explains the reduction in sensible heat variance in the DEF experiment.

It is also noteworthy that the NE-DEF surface air temperature does not significantly differ from that of the NE-CTL run (Table 2). This could be explained by a compensating role of the different components of the surface energy balance, which is written as:

$$
\frac{\partial \mathrm{E}_{s}}{\partial t}=R_{s}-L E-S H
$$


where $E_{\mathrm{s}}$ indicates the energy content of the soil, $R_{\mathrm{s}}$ is the net surface radiation defined as the sum of shortand long-wave contributions and $L E$ and $S H$ refer to latent and sensible fluxes, respectively. The enhanced evaporation moistens the lower troposphere which, in turn, generates more clouds, which causes a decrease in the downward short-wave radiation but an increase in the downward long-wave radiation. The net terms of short- and long-wave radiation are shown in Fig. 4c and $d$, respectively. In order to account for the surface energy balance, for any given PDF of Fig. 4 we computed the areas (as definite integrals), since, unlike the mean values, these also take into account the variance of the PDFs. By solving the surface energy balance equation, results show that the energy budget does not
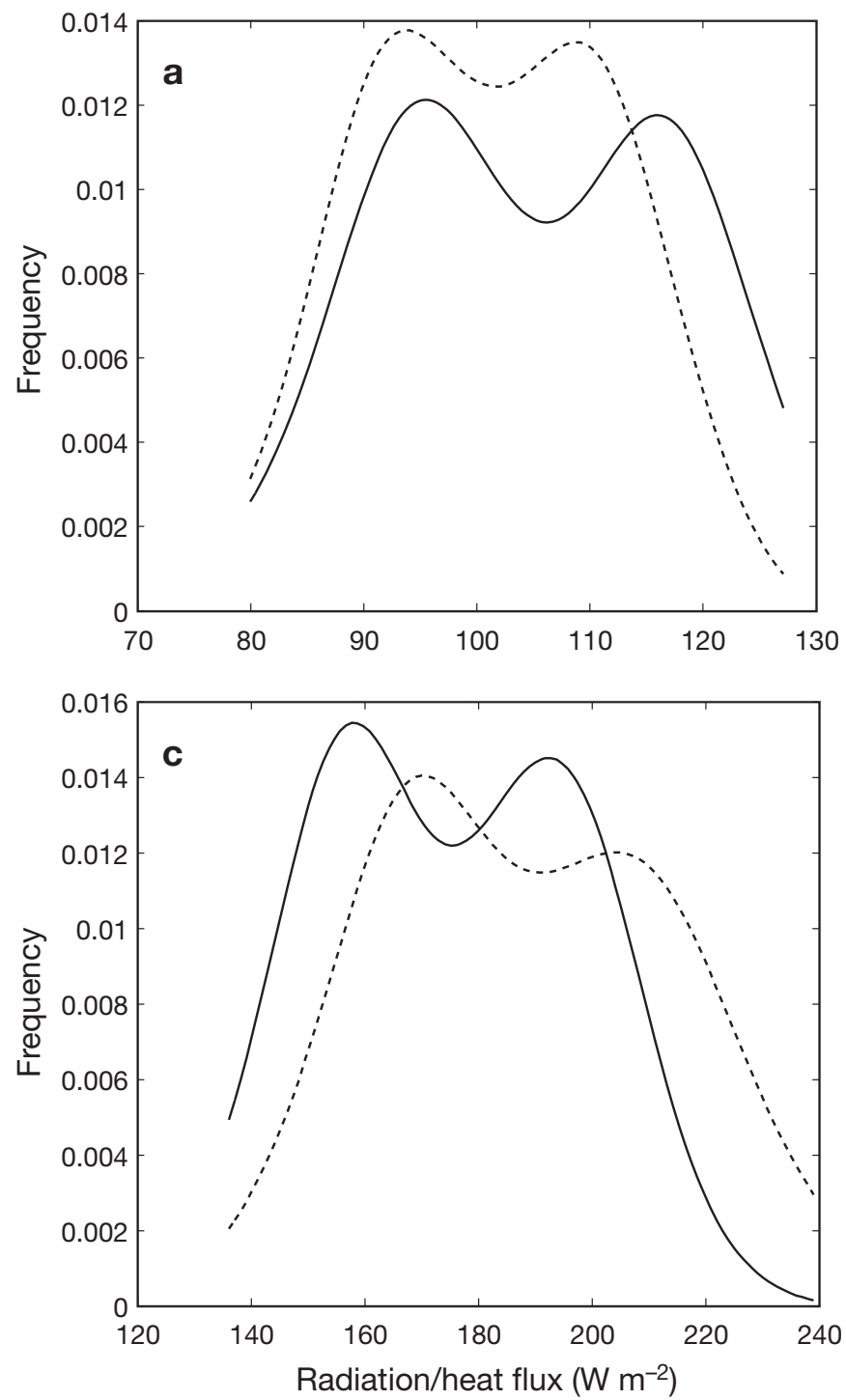

change much between the NE-CTL and NE-DEF simulations. As a consequence, weak and non-significant decreases in surface temperature were found.

Concerning the AFF simulation, and hence the fluxes computed for the CE subregion, both the CECTL and CE-AFF latent heat fluxes show a bimodal behavior (Fig. 5a), with a marked tendency to reduce the evaporation in the CE-AFF case, likely due to increased stomatal resistance, which in summer limits the evapotranspiration. As previously explained, the bimodality is mainly due to the difference in the soil moisture conditions during June-July and August. In central Europe, where the main LCC of the AFF simulation occurs, the components of surface hydrological cycle (latent heat and soil moisture) are characterized
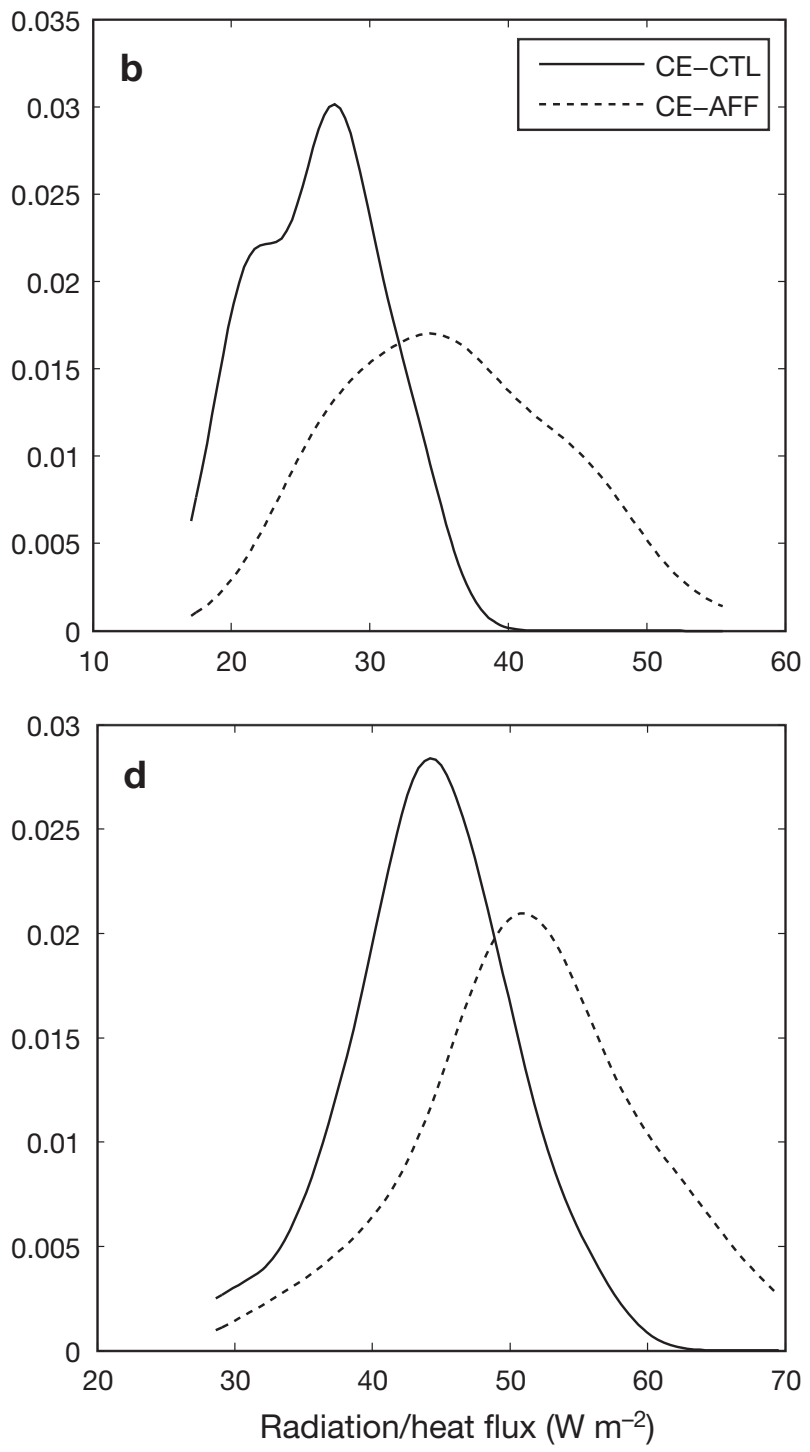

Fig. 5. Probability distribution of summer (June-August) (a) latent heat, (b) sensible heat, (c) net shortwave radiation and (d) net longwave radiation computed over a small domain falling in the afforested area $\left(0^{\circ}\right.$ to $20^{\circ} \mathrm{E}, 48^{\circ}$ to $\left.52^{\circ} \mathrm{N}\right)$. CE: central Europe; CTL: control run; AFF: afforestation simulation 
by progressive decreasing values from June to August due to upper layer limited moisture availability and closure of plant stomata.

The CE-AFF sensible heat flux shows a reversal behavior with respect to the NE-DEF case, i.e. the mean and the variance increased (Fig. 5b). As a matter of fact, the reduction of the latent heat is compensated for by the increase in the sensible heat flux mean, while the increase in the surface drag coefficient enhances the turbulence production and, in turn, the sensible heat variance.

Also in this case, it is noteworthy that the CE-AFF surface air temperature did not significantly differ from that of the CE-CTL run (Table 2). This could be explained by a compensating role of the different components of the surface energy balance. Fig. 5c and d show the net terms of short- and long-wave radiation, respectively. The changes in the PDFs (Fig. 5c,d) are mainly related to the reduced evaporation in $\mathrm{CE}-\mathrm{AFF}$ which dries the lower troposphere which, in turn, causes an increase in the incident short-wave but a decrease in the downward long-wave radiation. Additionally, by considering all the PDFs integral of Fig. 5 to solve the surface energy balance, we found that the differences in surface energy budget between CE-CTL and CE-AFF were reasonably low.

Unlike the net short-wave radiation PDF computed for the NE subregion (Fig. 4c), there is a strong bimodality in net short-wave radiation in the CE subregion (Fig. 5c) in both the CTL and AFF simulations. Generally, the bimodality could be related to different clear-sky/cloud conditions. However, the bimodality found in $\mathrm{CE}$ is related to the latent heat bimodality and is mainly due to the downward component. More precisely, by removing August, during which the soil is in a drier state and the latent heat shows a different equilibrium, the short-wave bimodality disappears, as does the latent heat bimodality. Since bimodal evapotranspiration leads to a water liquid content in the lower troposphere with the same shape, and RegCM3 uses the Delta-Eddington scheme (Briegleb 1992) which takes into account the water and cloud scattering to compute the downward radiation, the bimodality in the net short-wave radiation can be related to the latent heat biomodality.

\subsection{Differences in atmospheric circulation}

As regards induced mesoscale circulation, we verified how the previously analyzed changes in surface variables, such as surface fluxes, influence the lower tropospheric circulation. We analyzed the summer season, which showed significant differences in surface fields between perturbed and control runs. In Fig. 6, we show the wind vector and temperature anomalies at $960 \mathrm{hPa}$ for the DEF and AFF simulations. Since the larger changes in air temperature occur at $960 \mathrm{hPa}$, we refer to this level for the following analysis. Above $925 \mathrm{hPa}$, the LCC-induced climate changes are weakened and only marginally significant. The larger and significant change between $2 \mathrm{~m}$ and $960 \mathrm{hPa}$ temperature is mainly related to the differences in turbulent fluxes; as previously described (see Section 3.1), at soil level the changes in heat fluxes are compensated by the change in surface radiation so that the energy balance does not substantially change, and hence the $2 \mathrm{~m}$ temperature does not show significant changes. However, the modification of turbulent fluxes induced by LCC in turn modify the planetary boundary layer (PBL) height and the distribution of energy inside the lower troposphere. As a consequence, the $960 \mathrm{hPa}$ (and also the $925 \mathrm{hPa}$ ) temperature significantly differs from that of the CTL run.

The summer-averaged condition in the CTL run features an anti-cyclonic pattern covering most of central Europe and the Mediterranean region. In the DEF simulation, the stomatal resistance reduction (Table 2) leads to an increase in the evapotranspiration (see previous paragraph). Where the LCC takes place, the cooling at the surface, related to higher soil moisture and soil heat capacity, reduces the sensible heat flux. The other relevant change is the reduction in the surface friction due to LCC.

The differences in horizontal wind vectors between the DEF simulation and the CTL run shows an anticyclonic circulation at $960 \mathrm{hPa}$ located on the northeastern side of the Carpathian Mountains (Fig. 6a). The maximum temperature anomaly amounts to -1.8 $\mathrm{K}$. The anti-cyclonic circulation originates as a change of the surface friction owing to the substitution of mixed forest and evergreen needle-leaf forests with crops. The friction change directly affects the vorticity balance at the surface. According to the vorticity equation in the PBL, the friction creates a vertical gradient in vorticity. A secondary circulation then develops to reduce the vertical gradient of vorticity created by friction. The reduction of friction in the DEF simulation results in a reduced vertical vorticity gradient, and in anti-cyclonic circulation in the wind differences field. In our simulations, the analysis of fields related to the convection seems to suggest (i.e. no significant differences in the rainfall field and in turn in the latent heat release) that vorticity changes are mainly related to changes in friction. Nevertheless, further simulations should be performed in order to quantify the impact of thermally induced changes in vorticity.

In the AFF simulation (Fig. 6b), the surface difference flow features a large cyclonic circulation centered over the Adriatic Sea and covering most of the Euro- 


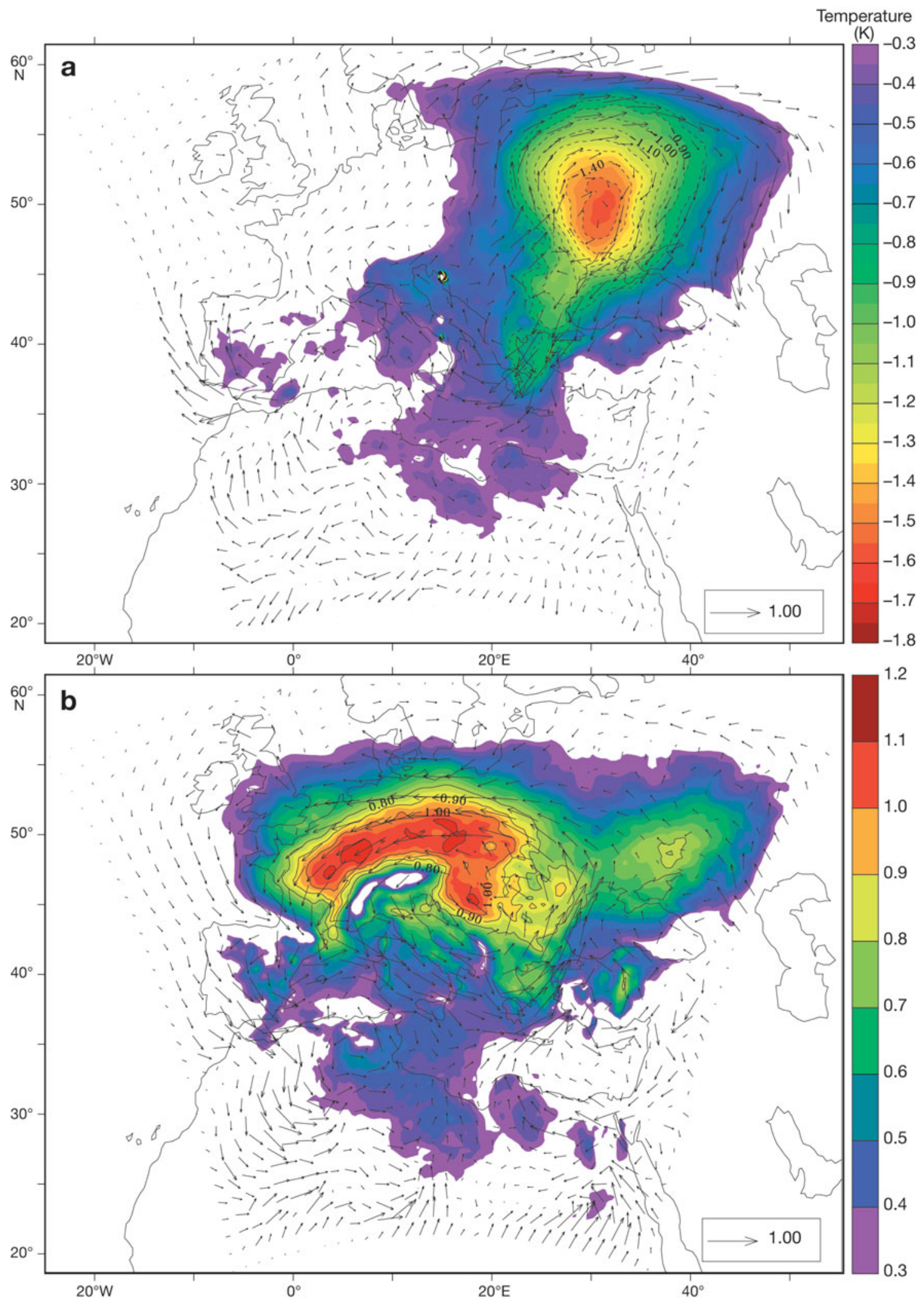

Fig. 6. Differences in horizontal wind vectors (arrows, $\mathrm{m} \mathrm{s}^{-1}$ ) and temperature (color scale, $\mathrm{K}$ ) at $960 \mathrm{hPa}$ over the summer season (June-August) between the control run and the (a) deforestation and (b) afforestation simulations. The contour lines indicate where these differences are statistically significant $(t$-test, $\mathrm{p}<0.01)$ 
pean continent. The maximum temperature change is over western-northern Europe, as is the change in the wind differences field. The maximum temperature anomaly amounts to $+1.2 \mathrm{~K}$. The cyclonic circulation originates from an increase in the surface friction as a result of the covering of most of the European continent with deciduous forests. Additionally, the friction change directly affects the vorticity balance at the surface. The increase in friction results in an enhanced vertical vorticity gradient for the AFF simulation, which produces the strong cyclonic circulation shown in Fig. 6b. The temperature increase in the PBL is mainly related to enhanced sensible heat flux of the AFF simulation (see Section 3.1.).

Two regional wind patterns were affected by the AFF simulation: the Aetesians and the Gulf of Lion winds. The cyclonic circulation weakens the Aetesians in our simulations. For the Gulf of Lion winds, the rising friction in the AFF simulation increases the northerly wind component, enhancing the wind channeling over the Rhône valley and resulting in a stronger wind over the Gulf of Lion with respect to the CTL run.

\subsection{Impact on extreme events}

Climate is defined not simply as average temperature and precipitation but also by the type, frequency and intensity of weather events. LCC-induced climate change has the potential to alter the prevalence and severity of extremes such as heat waves, cold spells, storms, floods and droughts. Though simulation of changes in these types of events under a changing climate and different boundary condition is difficult, understanding vulnerabilities to such changes is critical to the assessment of impacts on human health, society and the environment.

According to the IPCC definition (IPCC 2007), extreme events are commonly considered those rarer than the $1 \mathrm{st}, 5$ th or 10 th percentile (at one extreme) or the 90th, 95th or 99th percentile (at the other). Warm nights or hot days are those exceeding the 90th percentile of temperature, while cold nights or days are those falling below the 10th percentile. Heavy precipitation is defined as daily amounts greater than the 95th (or for 'very heavy', the 99th) percentile.

In the present study, climate extreme events are generally related to unusual values of daily maximum and minimum surface temperatures or precipitation amounts. Hence, changes in these variables between DEF and AFF simulations and the CTL run were analyzed, considering mean values and selected percentiles (90th for maximum temperature) to quantify the intensity of extreme events. Taking into account the maximum daily $2 \mathrm{~m}$ temperature, we found a high impact of LCCs on summer hot days. Fig. 7 shows the difference in the number of the days during which the temperature is >90th percentile between the 2 perturbed simulations and the CTL run. The values of the extreme temperature were computed from the CTL run; from this simulation we also computed the number of days with the daily maximum temperature above the threshold of the 90th percentile. Hence, this last step has been repeated in the DEF and AFF simulations, considering the CTL 90th percentile as the threshold to account for the number of summer hot days. Finally, we plotted the anomalies in term of days.

Results show a decrease in the number of summer hot days within the DEF simulation (Fig. 7a), with the greatest change (around $20 \mathrm{~d}$ ) centered in Eastern Europe, where the maximum LCC occurs. This result is in agreement with the results in Fig. 6a, indicating that deforestation induces a general cooling of surface and low troposphere temperature. On the other hand, the AFF simulation generates an increase in the number of summer hot days with respect to the CTL run (Fig. 7b). The area where a significant change in the frequency of summer hot days occurs covers all the afforested regions with maximum values up to $18 \mathrm{~d}$ in southern France and in Italy (south of the Alps).

To untangle which is the main mechanism responsible for these extremes, we repeated the same analysis considering the long-wave and short-wave fluxes and sensible heat flux variables (data not shown). In the former case, we considered the effect of the lower tropospheric moistening or drying on the surface radiative balance, and consequently on the surface temperature. In the latter case, we examined the effect of the surface drag change due to LCCs on the variability of the sensible heat flux and, in turn, on the surface temperature. Based on such an analysis, our results point out that the sensible heat flux is the main variable affecting the change in distribution of temperature (i.e. extremes).

These results suggest that the decrease (increase) in the number of summer hot days in DEF (AFF) simulations is mainly due to a change in sensible heat flux extremes. The modifications of sensible heat PDF are mainly due to change of the surface drag, and consequently of the turbulent fluxes within the PBL. The change in the turbulent fluxes affects the variability of the $2 \mathrm{~m}$ temperature PDF, and consequently the extremes, while the reasonably low differences in surface energy budget between the control and the LCC experiments, leaving the $2 \mathrm{~m}$ temperature mean unchanged.

For precipitation, we found that LCC does not generate changes in summer heavy rain events in the DEF or the AFF simulations. 

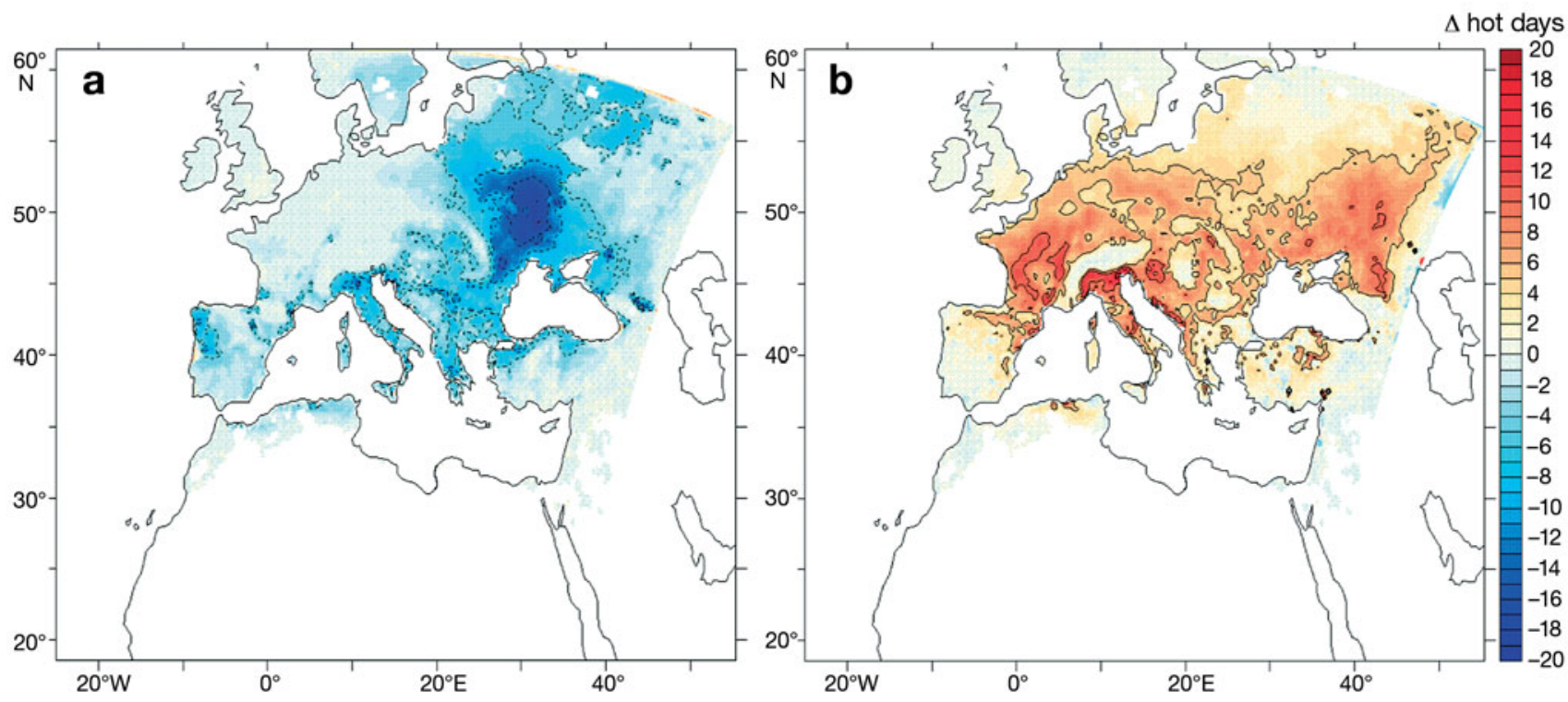

Fig. 7. Change in the number of summer hot days between the control run and the (a) deforestation and (b) afforestation simulations. A hot day occurs when the daily maximum temperature is greater than the 90th percentile of the control run

\section{DISCUSSION}

In the present study, certain land-atmosphere interactions were investigated by means of the regional climate model RegCM3 to identify the sensitivity of the local and regional climate to deforestation and afforestation in the Euro-Mediterranean area. The deforestation scenario represents an extreme substitution (forests with crops), especially in eastern Europe where the main forests are located. The changes in the AFF experiment, which lead to a substitution of crops with forests, are spread over a relatively larger area covering almost all of central Europe.

The simulation results show how LCCs are able to modify both the thermodynamics and dynamics of the lower troposphere in central Europe, particularly during summer. During winter, the European atmospheric conditions are influenced by translating and developing synoptic-scale disturbances, which are advected into the model domain through its lateral boundaries (Heck et al. 2001). As a consequence, vegetationinduced effects cannot locally accumulate to substantial amplitude, so only weak changes were found during winter in both the DEF and AFF simulations. During summer, the weather in southern-central Europe is frequently characterized by the occurrence of highpressure systems with weak large-scale advection, and hence favourable meteorological conditions to analyze the intrinsic atmospheric sensitivity to the land surface (Heck et al. 2001). We found significant changes in surface climate with regard to heat fluxes, while both temperature and precipitation showed just a few significant points spread over the domain.
In the DEF simulation, the significant changes in latent (and sensible) heat are confined mainly to eastern Europe, where the main LCCs take place. In winter, the LCCs induce a reduction of the evapotranspiration owing to the lower transpiration of the grass with respect to mixed forest. On the other hand, in summer a reversal in sign of latent heat occurs. The enhanced summer evapotranspiration in the DEF simulation is due to a greater amount of water in the soil layers with respect to the control run as a consequence of less evapotranspiration during winter, and to a different partition of the available surface energy between sensible and latent heat fluxes due to drag coefficient change.

In the AFF simulation, we observed a reverse behaviour with reduced evapotranspiration and increased sensible heat flux during summer. As a matter of fact, the LCC modifies the evaporation by increasing the stomatal resistance and the sensible heat flux by increasing the surface drag coefficient. Both changes concur to reduce the evaporation during summer and, therefore, to increase the sensible heat variance.

Despite the significant differences in surface fluxes, $t$-test results showed that mean temperature in the DEF and AFF simulations is the same as the mean temperature in the CTL run; in other words, the LCC does not affect the mean surface temperature (and precipitation). However, significant vegetation-induced changes in temperature have been found in the lower troposphere for summer. Deforestation results in a cooling of the lower atmosphere, while afforestation leads to a warming of PBL. These changes are mainly ascribable to the reduction (increase) of friction in the 
DEF (AFF) simulation which results in a reduced (increased) sensible heat flux and vertical vorticity gradient, and in anti-cyclonic (cyclonic) circulation in the wind differences field.

Finally, a novel feature of the present study is the analysis of the LCC-induced extremes. As stated, in these simulations LCCs do not affect the mean of the 2 $\mathrm{m}$ temperature but has a strong impact on the upper tail. We found a high impact of LCCs on the frequency of heat waves (i.e. temperatures greater than 90th percentile). In particular, the DEF simulation decreases the number of summer hot days, while the AFF simulation increases the number of summer hot days. These results agree with the cooling (warming) that deforestation (afforestation) induces in the PBL. Moreover, the analysis of the surface flux extremes suggests that the decrease (increase) in the number of summer hot days in DEF (AFF) simulations is mainly due to a change in the sensible heat flux extremes, which in turn is ascribable to the change of the surface drag and, consequently, to the turbulent fluxes.

In contrast with previous experiments performed for the European domain, we found that the mean surface temperatures show only weakly significant changes with respect to the CTL run, and the changes in heat flux (mainly latent heat) do not significantly affect summer precipitation. In addition, if we consider the temperature at $960 \mathrm{hPa}$ and the upper tail of the temperature PDF, our model results agree with the results of other simulations (Dumeniel Gates \& Ließ 2001) performed on Euro-Mediterranean regions. Specifically, as shown in Dumenil-Gates \& Ließ (2001), the DEF simulation leads to a cooling of lowerlevel temperature, while the AFF simulation induces a warming of surface temperature. Heck et al. (2001) also showed a warming in the summer temperature in their afforestation simulation, although the magnitude of the change is not the same as in the present study. However, the difference in terms of amplitude in these results are not surprising because they are strictly affected by the characteristics of the replacement vegetation and the sensitivity of the land surface scheme.

Finally, it is worth noting that this model configuration does not account for the terrestrial carbon cycle and does not compute how it affects climate; hence the results of the cooling (warming) owing to the DEF (AFF) simulation could be slightly different if we also take into account how LCCs modify the greenhouse gas composition.

Acknowledgements. We gratefully acknowledge the ECMWF for the use of the ERA-40 data. The authors wish also to thank 2 anonymous reviewers for their helpful reviews of the manuscript.

\section{LITERATURE CITED}

Artale V, Calmanti S, Carillo A, Dell'Aquila A and others (2009) An atmosphere-ocean regional climate model for the Mediterranean area: assessment of a present climate simulation. Clim Dyn doi:10.1007/s00382-009-0691-8

Betts RA (2001) Biogeophysical impacts of land use on present-day climate: near-surface temperature change and radiative forcing. Atmos Sci Lett 2:39-51

Briegleb BP (1992) Delta-Eddington approximation for solar radiation in the NCAR community climate model. J Geophys Res 97:7603-7612

Christensen JH, Machenhauer B, Jones RG, Schar C, Ruti PM, Castro M, Visconti G (1997) Validation of present-day regional climate simulations over Europe: LAM simulations with observed boundary conditions. Clim Dyn 13: 489-506

Dickinson RE, Henderson-Sellers A, Kennedy PJ (1993) Biosphere-Atmosphere Transfer Scheme (BATS) Version 1e as coupled to the NCAR community climate model. NCAR Technical Note, NCAR/TN-387+STR, National Center for Atmospheric Research, Boulder, CO

> Dumenil Gates L, Ließ S (2001) Impacts of deforestation and afforestation in the Mediterranean region as simulated by the MPI atmospheric GCM. Global Planet Change 30: 309-328

Fahey B, Jackson RB (1997) Hydrological impacts of converting native forests and grasslands to pine plantations, South Island, New Zealand. Agric For Meteorol 84:69-82

Ferranti L, Viterbo P (2006) The European summer of 2003: sensitivity to soil water initial conditions. J Clim 19: $3659-3680$

Findell KL, Shevliakova E, Milly PCD, Stouffer RJ (2007) Modeled impact of anthropogenic land cover change on climate. J Clim 20:3621-3634

Fouillet A, Rey G, Laurent F, Pavilion G and others (2006) Excess mortality related to the August 2003 heat wave in France. Int Arch Occup Environ Health 80:16-24

- Gaertner MA, Christensen OB, Prego JA, Polcher J, Gallardo C, Castro M (2001) The impacts of deforestation on the hydrological cycle in the western Mediterranean: an ensemble study with two regional models. Clim Dyn 17: $857-873$

Giorgi F (1990) Simulation of regional climate using a limited area model nested in a general circulation model. J Clim 3: 941-963

Giorgi F, Mearns LO (1991) Approaches to regional climate change simulation: a review. Rev Geophys 29:191-216

Giorgi F, Mearns LO (1999) Introduction to special section: regional climate modeling revisited. J Geophys Res 104: $6335-6352$

> Giorgi F, Marinucci MR, Bates GT (1993a) Development of a second generation regional climate model (RegCM2). I. Boundary-layer and radiative transfer processes. Mon Weather Rev 121:2794-2813

Giorgi F, Marinucci MR, Bates GT, De Canio G (1993b) Development of a second generation regional climate model (RegCM2). II. Convective processes and assimilation of lateral boundary conditions. Mon Weather Rev 121:2814-2832

Giorgi F, Bi X, Pal JS (2004) Mean, interannual variability and trends in a regional climate change experiment over Europe. I. Present-day climate (1961-1990). Clim Dyn 22: 733-756

> Heck P, Luthi D, Wernli H, Schar C (2001) Climate impacts of European-scale anthropogenic vegetation changes: a sensitivity study using a regional climate model. J Geophys Res 106:7817-7835 
IPCC (2007) Climate change 2007: the physical science basis. Contribution of Working Group I to the Fourth Assessment Report of the Intergovernmental Panel on Climate Change. Cambridge University Press, Cambridge

Jacob D, Bäring L, Christensen OB, Christensen JH and others (2007) An inter-comparison of regional climate models for Europe: model performance in present-day climate. Clim Change 81:31-52

Koster RD, and 24 others (2004) Regions of strong coupling between soil moisture and precipitation. Science 305: 1138-1140

Loveland TR, Merchant JW, Ohlen DO, Brown JF (1991) Development of a land cover characteristics database for the conterminous United States. Photogramm Eng Remote Sensing 57:1453-1463

Loveland TR, Reed BC, Brown JF, Ohlen DO, Zhu Z, Yang L, Merchant JW (2000) Development of a global land cover characteristics database and IGBP DISCover from $1 \mathrm{~km}$ AVHRR data. Int J Remote Sens 21:1303-1330

Middleton N, Thomas D (1997) World atlas of desertification. Arnold, London

Nosetto MD, Jobbagy EG, Paruelo JM (2005) Land-use change and water losses: the case of grassland afforestation across a soil textural gradient in central Argentina. Glob Change Biol 11:1101-1117

Pal JS, Small EE, Eltahir EAB (2000) Simulation of regionalscale water and energy budgets: representation of subgrid cloud and precipitation processes within RegCM. J Geophys Res 105:29579-29594

Pal JS, Giorgi F, Bi X, Elguindi N, and 16 others (2007) Regional climate modelling for the developing world: the ICTP RegCM3 and RegCNET. Bull Am Meteorol Soc 88: 1395-1409

Pielke RA, Adegoke J, Beltran-Przekurat A, Hiemstra CA and others (2007) An overview of regional land-use and landcover impacts on rainfall. Tellus 59:587-601

Pitman AJ (2003) The evolution of, and revolution in, land surface schemes designed for climate models. Int J Climatol 23:479-510

Editorial responsibility: Filippo Giorgi,

Trieste, Italy
Reale O, Shukla J (2000) Modeling the effects of vegetation on Mediterranean climate during the Roman classical period: II. Model simulation. Global Planet Change 25:185-214

> Reynolds RW, Rayner NA, Smith TM, Stokes DC, Wang W (2002) An improved in situ and satellite SST analysis for climate. J Clim 15:1609-1625

Ruti PM, Bargagli A, Cacciamani C, Paccagnella T, Cassardo C (1998) LAM multi-seasonal numerical integrations: performance analysis with different surface schemes. Beitr Phys Atmos 71:321-346

> Sanchez E, Gaertner MA, Gallardo C, Padorno E, Arribas A, Castro M (2007) Impacts of a change in vegetation description on simulated European summer present-day and future climates. Clim Dyn 29:319-332

Schär C, Vidale PL, Lüthi D, Frei C, Häberli C, Liniger MA, Appenzeller $C$ (2004) The role of increasing temperature variability in European summer heat waves. Nature 427: 332-336

Seneviratne S, Luthi D, Litschi M, Schar C (2006) Landatmosphere coupling and climate change in Europe. Nature 443:205-209

Suh MS, Lee DK (2004) Impacts of land use/cover changes on surface climate over east Asia for extreme climate cases using RegCM2. J Geophys Res 109:D02108 doi: 10.1029/ 2003JD003681

Uppala SM, Kållberg PW, Simmons AJ, Andrae U, and 42 others (2005) The ERA-40 re-analysis. Q J R Meteorol Soc 131:2961-3012

> Vautard R, Yiou P, D'Andrea F, De Noblet N and others (2007) Summertime European heat and drought waves induced by wintertime Mediterranean rainfall deficit. Geophys Res Lett 34:L07711 doi: 10.1029/2006GL028001

Xue Y, Shukla J (1993) The influence of land surface properties on Sahel climate. I. Desertification. J Clim 6:2232-2245

Xue Y, Shukla J (1996) The influence of land surface properties on Sahel climate. II. Afforestation. J Clim 9:3260-3275

Zaitchik BF, Macalady AK, Bonneau LR, Smith RB (2006) Europe's 2003 heat wave: a satellite view of impacts and land-atmosphere feedbacks. Int J Climatol 26:743-769

Submitted: July 10, 2009; Accepted: December 10, 2009

Proofs received from author(s): March 5, 2010 